\title{
DIETARY PATTERN AND NUTRIENT INTAKE OF OVERWEIGHT AND NORMAL WEIGHT ADOLESCENT GIRLS - A CROSS-SECTIONAL STUDY
}

\author{
ASMA PARVEEN N, SHEILA JOHN*, SARAH JANE MONICA \\ Department of Home Science, Women's Christian College, Chennai, Tamil Nadu, India. Email: sheila.research16@gmail.com
} Received: 22 August 2017, Revised and Accepted: 14 October 2017

\section{ABSTRACT}

Objective: The objective of the study was to evaluate and compare the dietary pattern and nutrient intake of overweight and normal weight adolescent girls.

Methods: A cross-sectional study was conducted among 200 adolescent girls aged 18-22 years. Information regarding demographic profile and the dietary pattern was obtained using a questionnaire. Anthropometric measurements such as height, body weight, and waist circumference were measured and body fat percentage was estimated. Nutrient intake was calculated using 3 days dietary recall method. In addition, a nutrition education program was conducted to create an impact on the dietary habits.

Results: The study showed that majority of the subjects in both the groups was non-vegetarians. With regards to meal skipping, $76 \%$ of the overweight girls had the habit of skipping meal and breakfast was the most common meal that was skipped. There was a significant difference in the anthropometric indices and nutrient intake between normal and overweight subjects. Subjects in both the groups were fond of eating junk foods followed by inadequate intake of fruits. Nutrition education program helped them to change their dietary habits.

Conclusion: Providing nutrition education to adolescents is essential as it creates an impact on the eating habits by modifying their dietary pattern and creating awareness about the ill health effects of junk food consumption.

Keywords: Adolescent girls, Nutritional status, Nutrition education, Dietary habits.

(c) 2018 The Authors. Published by Innovare Academic Sciences Pvt Ltd. This is an open access article under the CC BY license (http://creativecommons. org/licenses/by/4. 0/) DOI: http://dx.doi.org/10.22159/ajpcr.2018.v11i1.22178

\section{INTRODUCTION}

The term "adolescence" is derived from the Latin verb "adolescere," which means "grow to maturity." Adolescents are considered to be a unique target group as optimal growth during this period is considered to be of prime importance in maintaining good health thereafter. In addition, transition from childhood to adolescence creates special nutritional needs for growth and development that have to be provided through proper eating habits and dietary pattern [1]. Currently, it is estimated that there are about 69.7 million adolescent girls constituting about $7.0 \%$ of the total population. Research has reported that establishing proper dietary habits in adolescence decreases the risk of morbidities such as undernutrition, being overweight or obese, and micronutrient deficiencies and also prevents the risk of developing other chronic illness such as hypertension, diabetes, and cardiovascular diseases [2].

Following undesirable or faulty eating habits such as skipping of meals, low intake of fruits and vegetables, consumption of fast foods, and eating away from home is common among adolescent girls which is associated with diet-related chronic illness [3]. Consumption of foods rich in saturated fats, refined sugar, and energy dense caloric foods are common in this age group. Popularization of these foodstuffs in this age is due to certain factors such as peer influence advertising through social and public media, socioeconomic status of household, quick preparation, great taste, and attractive appearance $[4,5]$.

Since the dietary pattern of adolescents encounters dramatic changes, recognizing them and bringing a change in their food consumption pattern is essential in improving the health status of future adults. Although many studies reveal that some of these patterns are likely to be common among adolescent girls, very little information is available. In spite of knowing the detrimental effects of following unhealthy food habits, adolescent girls still continue to follow this food pattern because of which providing nutrition education program is essential as it helps to improve health outcomes and foster healthy eating. Therefore, the present study was carried out among adolescents with the following objectives:

1. To assess the dietary pattern of adolescent girls.

2. To measure anthropometric indices such as height, body weight, waist circumference, and calculate body fat percentage.

3. To calculate the nutrient intake using $24 \mathrm{~h}$ dietary recall for 3 days and to compare with recommended dietary allowances (RDA).

4. To conduct and assess impact of nutrition education program.

\section{METHODS}

A cross-sectional study design was adopted for the study. The study protocol was reviewed and approved by the Institutional Independent Ethics Committee before the commencement of the study.

\section{Sample selection}

Two hundred college-going adolescent girls aged 18-22 years were selected using purposive sampling technique. The subjects were categorized into two groups, namely, overweight and normal adolescent girls based on body mass index (BMI) cut off as it is an age-independent anthropometric criteria [6].

Criteria for sample selection

\begin{tabular}{ll}
\hline Inclusion criteria & Exclusion criteria \\
\hline $\begin{array}{l}\text { Subjects willing to participate } \\
\text { in the study }\end{array}$ & Subjects having eating disorders \\
$\begin{array}{l}\text { Subjects should not be suffering } \\
\text { from any illness }\end{array}$ & $\begin{array}{l}\text { Subjects who are on restrictive } \\
\text { diet }\end{array}$ \\
\hline
\end{tabular}

Tools for data collection

Questionnaire

A structured questionnaire was used to elicit general information regarding demographic profile such as age, educational qualification, 
socioeconomic status, and dietary pattern of the subjects who participated in the study.

\section{Anthropometric measurements}

Anthropometric measurements assess the nutritional status of the individual by assessing the size, proportion, and composition of the human body. It is widely used for assessing nutritional problems and its relation with other chronic diseases. It reflects both the health and nutritional status of the population and is used as a tool for guiding public health policy.

\section{Body weight}

The weight was recorded using a portable weighing scale which was adjusted to zero error. The subjects were requested to stand erect barefoot on the weighing scale with normal light clothing, and the weight was recorded to the nearest $0.1 \mathrm{~kg}$.

\section{Height}

The height of the subjects was measured using a non-flexible measuring tape. The height was measured and recorded in centimeters for each subject.

\section{Waist circumference}

The most valuable and practical indicator of fat distribution and abdominal fat is a person's waist circumference. Waist circumference was measured by placing a non-stretchable tape around the person's body, crossing just above the upper hip bones and making sure that the tape remains on a level horizontal plane on all sides. The tape was tightened slightly, but without compressing the skin and was measured to the nearest $0.1 \mathrm{~cm}$.

\section{Percentage body fat}

The body fat percentage was calculated using the formula

Body fat percentage $=(1.37 \times$ body mass index $)-3.467$

\section{Dietary pattern and nutrient intake}

Information regarding meal pattern, eating habits, and also the frequency of consumption of foods was also obtained using a questionnaire. 3 days dietary recall method was used to calculate the nutrient intake of the subjects. In this method, the subjects were asked to recollect what the foods and the beverages they had consumed for the past 3 days. The methodology adopted for the study is schematically represented in (Fig. 1).

\section{Statistical analysis}

The data obtained were coded and entered into Microsoft Excel 2010. Statistical tests such as t-test and Chi-square test were performed using Statistical Package for Social Sciences. Statistical significance was accepted at $\mathrm{p}<0.01$.

\section{RESULTS}

Table 1 summarizes that the subjects who participated in the study were aged between 18 and 22 years. With regard to educational qualification, $50 \%$ of the subjects were postgraduates in both the groups. It is also evident from Table 1 that around $60 \%$ of the subjects in both the groups were categorized under upper middle class. It might be proposed that subjects whose parent income is high are less likely to control their children and given greater independence, which affects the food consumption pattern of the children, leading to increased risk of overweight.

The mean height of overweight adolescent girls was $158.00 \pm 7.03 \mathrm{~cm}$ and $157.00 \pm 5.81$ for normal adolescent girls. The mean weight of overweight and normal adolescent girls was $69.83 \pm 6.82 \mathrm{~kg}$ and $51.83 \pm 5.40 \mathrm{~kg}$, respectively. It is also observed that mean waist circumference of girls with normal BMI was $<80 \mathrm{~cm}$. The mean body percentage was $34.77 \pm 3.22 \%$ for overweight girls while it was $25.28 \pm 1.83 \%$ for normal adolescent girls (Table 2).

It is clear that $46 \%$ of overweight subjects and $7 \%$ of normal subjects came under action Level II indicating high odds ratio for cardiovascular risk factors. $93 \%$ of normal subjects were found to have waist circumference $<80 \mathrm{~cm}$ (Table 3). A significant association was observed between BMI and waist circumference.

Table 4 summarizes that $89 \%$ of overweight subjects and $79 \%$ of normal weight subjects were non-vegetarians. With regard to meal consumption pattern of the subjects, $57 \%$ of overweight subjects consumed more than three meals a day while $61 \%$ of normal weight subjects had the habit of consuming three meals per day.

Table 1: Percentage distribution of subjects based on demographic profile

\begin{tabular}{lll}
\hline Particulars & Over weight & Normal weight \\
\hline Age (years) & & \\
18 & 12 & 17 \\
19 & 8 & 28 \\
20 & 23 & 3 \\
21 & 26 & 29 \\
22 & 31 & 23 \\
Educational qualification & & \\
$\quad$ Undergraduates & 46 & 50 \\
Postgraduates & 54 & 50 \\
Socioeconomic class & & \\
$\quad$ Upper class & 33 & 28 \\
Upper middle class & 61 & 67 \\
Lower middle class & 6 & 5 \\
\hline
\end{tabular}

Table 2: Comparison of anthropometric measurements between normal and overweight subjects

\begin{tabular}{|c|c|c|c|}
\hline Anthropometric indices & Mean \pm SD & t value & p value \\
\hline \multicolumn{4}{|l|}{ Height $(\mathrm{cm})$} \\
\hline Normal & $157.00 \pm 5.81$ & 1.42 & $0.16^{\mathrm{NS}}$ \\
\hline Overweight & $158.00 \pm 7.03$ & & \\
\hline \multicolumn{4}{|l|}{ Weight (kg) } \\
\hline Normal & $51.83 \pm 5.40$ & 20.76 & $0.00^{* *}$ \\
\hline Overweight & $69.83 \pm 6.82$ & & \\
\hline \multicolumn{4}{|l|}{ Waist circumference $(\mathrm{cm})$} \\
\hline Normal & $72.91 \pm 4.42$ & 0.97 & $0.00^{* *}$ \\
\hline Overweight & $80.55 \pm 4.61$ & & \\
\hline \multicolumn{4}{|l|}{ Percentage body fat } \\
\hline Normal & $25.28 \pm 1.83$ & 0.00 & $0.00^{* *}$ \\
\hline Overweight & $34.77 \pm 3.22$ & & \\
\hline
\end{tabular}

**: Significant at $\mathrm{p}<0.01$, NS: Not significant, SD: Standard deviation

PHASE I: To elicit information regarding demographic profile and dietary pattern of adolescent girls

PHASE II: Anthropometric measurements Height, weight, waist circumference, and body fat percentage

PHASE III: To calculate the nutrient intake using 24 hour dietary recall method for 3 days

To conduct and assess the impact of nutrition education program

Fig. 1: Methodology adopted for the study 
Table 3: Percentage distribution of subjects based on waist circumference

\begin{tabular}{lcc}
\hline Waist circumference $\mathbf{( c m )}$ & Overweight \\
\hline$<80$ & \multicolumn{2}{c}{54} \\
$>80$ & 46 \\
\hline **: Significant at $p<0.01$ & \\
\multicolumn{3}{c}{ Table 4: Percentage distribution of subjects based on dietary } \\
practices \\
\multicolumn{3}{c}{} \\
\hline Particulars & Over weight & Normal weight \\
\hline Type of diet & 19 & 11 \\
Vegetarian & 79 & 89 \\
Non-vegetarian & 2 & 0 \\
Ovo vegetarian & & 1 \\
Number of meals consumed & 4 & 2 \\
1 & 4 & 40 \\
2 & 61 & 57 \\
3 & 31 & \\
More & & \\
\hline
\end{tabular}

With regard to skipping of meals, $73 \%$ of overweight subjects had the habit of skipping their meals and very often breakfast was found to be skipped by the subjects. Breakfast which is considered to be the most important meal of the day was frequently skipped by the subjects. Regular consumption of breakfast can positively impact children's health and well-being. On the other hand, parents should also encourage the children to consume breakfast regularly (Fig. 2).

Intake of junk foods is a recognizable aspect of teenage food behavior. With regard to consumption of junk foods, it was found that majority of the subjects in both the groups had the habit of eating junk foods (Fig. 3).

It is clear that $77 \%$ normal weight subjects had the habit of including fruits 3 or 4 times a week in their diet when compared to overweight subjects (Fig. 4). Inclusion of fruits on a regular basis is important as they a rich source of minerals, vitamins, phytochemicals, fiber, and antioxidants which lowers the risk of several long-term chronic illness.

The mean nutrient intake for both the groups is presented in Table 5. The intakes of all the nutrients were more than the RDA. Nutrient intake was found to be high among overweight subjects than the RDA ( $p<0.01)$.

Results of the test of significance reveal that there is a significant difference in nutrition knowledge and nutrition awareness among the subjects before and after the nutrition education program $(\mathrm{p}<0.01)$ Table 6 . The results also clearly portrait that conducting such program creates awareness on health hazards of junk foods among adolescents thereby modifying their dietary pattern and preventing health problem related to junk food.

\section{DISCUSSION}

Adolescence is a period of rapid growth and development bridging childhood and adulthood. Practicing healthy eating behaviors is one of the most important factors to meet the nutritional needs of adolescents, and proper eating behaviors that are learned in early life are maintained in adulthood thereby reducing the risk for major chronic disease [7].

In the present study, the age group of the subjects was 18-22 years and $60 \%$ of the subjects in both the groups belonged to upper middle class. There is an inverse association between socioeconomic status and the nutritional status of children and adolescents as it has a significant effect on food intake [8]. With regard to anthropometric indices, the mean body weight, body fat percentage, and waist circumference were found to be high than that of normal adolescent girls $(\mathrm{p}<0.01)$.

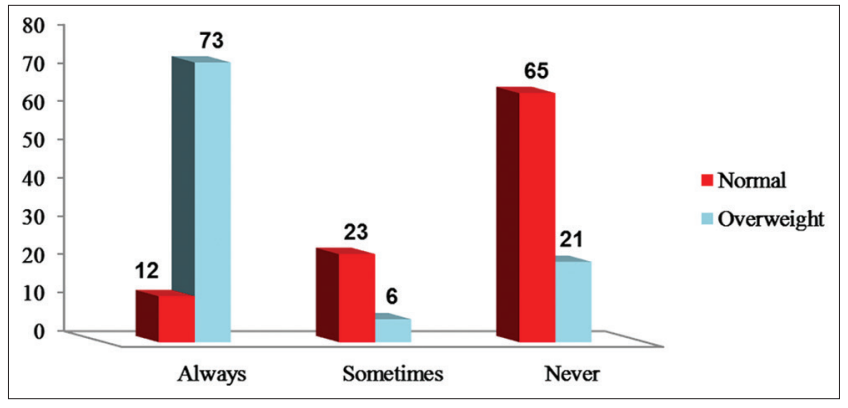

Fig. 2: Habit of skipping meals

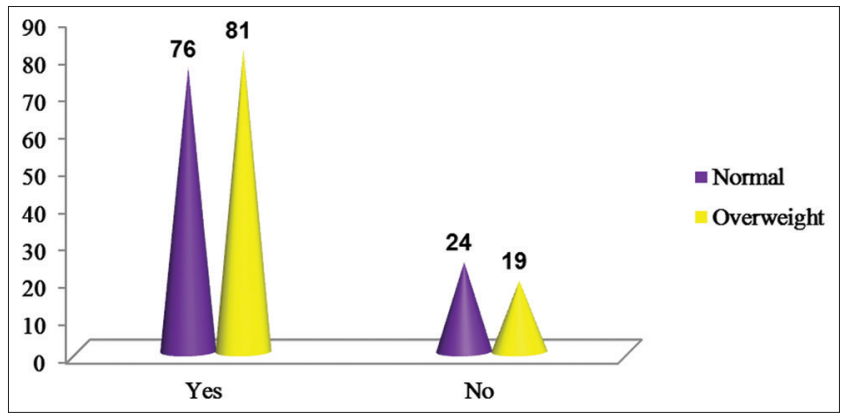

Fig. 3: Consumption of junk foods

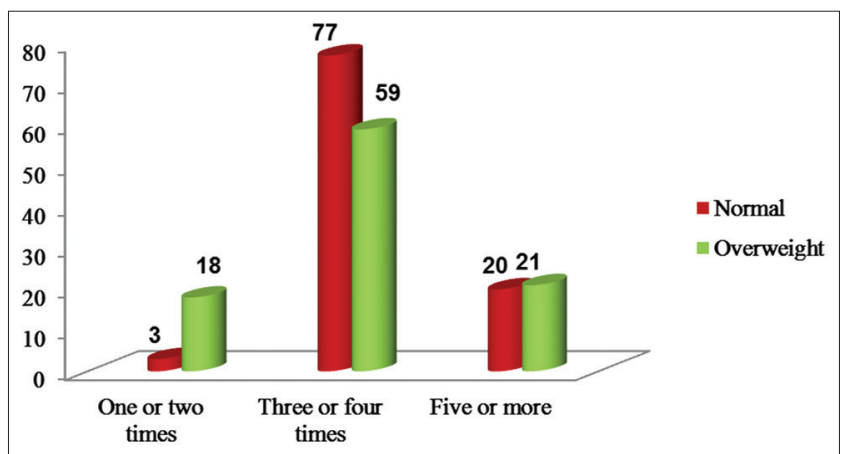

Fig. 4: Fruit consumption pattern

Majority of the subjects in both the groups were non-vegetarians while only a few percent of them were vegetarians. Regular meal consumption among adolescents is vital for providing adequate energy. With regard to meal skipping, $73 \%$ of overweight subjects had the habit of skipping meal, and breakfast was the most common skipped meal. Skipping breakfast leads to overeating at meals or drink sugarsweetened beverage that increases the calorie intake, leading to weight gain. Story et al. [9] also reported that females had the habit of skipping meals more often than males.

Globalization and modern urbanization have greatly influenced one's eating habits and forced many people to consume fancy and highcalorie fast foods, popularly known as junk foods. The results of the study indicated that majority of the subjects in both the groups were fond of eating junk foods. Junk foods refer to those food items which are perceived to have little or no nutritional value and also have ingredients 
Table 5: Nutrient intake of subjects in comparison to RDA

\begin{tabular}{|c|c|c|c|c|c|}
\hline Nutrients & Categories & Actual intake Mean \pm SD & Recommended intake (per day) & t value & $p$ value \\
\hline \multirow[t]{2}{*}{ Energy (Kcal) } & Normal & $1578.91 \pm 332.76$ & 1900 & -5.93 & $0.00 * *$ \\
\hline & Overweight & $2381.88 \pm 896.46$ & & & \\
\hline \multirow[t]{2}{*}{ Proteins (g) } & Normal & $71.98 \pm 112.73$ & 55 & 0.52 & $0.60^{\mathrm{NS}}$ \\
\hline & Overweight & $63.60 \pm 14.36$ & & & \\
\hline \multirow[t]{2}{*}{ Fat (g) } & Normal & $58.06 \pm 21.37$ & 20 & -4.06 & $0.00 * *$ \\
\hline & Overweight & $76.64 \pm 24.31$ & & & \\
\hline Carbohydrates (g) & Normal & $394.97 \pm 52.79$ & 475 & -7.40 & $0.00 * *$ \\
\hline \multirow[t]{2}{*}{ Fiber (g) } & Normal & $17.13 \pm 5.06$ & 25 & -6.99 & $0.00^{* *}$ \\
\hline & Overweight & $27.66 \pm 389.36$ & & & \\
\hline \multirow[t]{2}{*}{ Calcium (mg) } & Normal & $549.58 \pm 275.03$ & 600 & -3.72 & $0.00 * *$ \\
\hline & Overweight & $733.72 \pm 216.61$ & & & \\
\hline \multirow[t]{2}{*}{ Iron (mg) } & Normal & $13.10 \pm 2.07$ & 17 & -6.62 & $0.00^{* *}$ \\
\hline & Overweight & $17.32 \pm 4.00$ & & & \\
\hline
\end{tabular}

**: Significant at $\mathrm{p}<0.01$. SD: Standard deviation, RDA: Recommended dietary allowances

Table 6: Impact of nutrition knowledge and awareness

\begin{tabular}{llll}
\hline $\begin{array}{l}\text { Nutrition education } \\
\text { program }\end{array}$ & Mean \pm SD & t value & p value \\
\hline $\begin{array}{l}\text { Before nutrition education } \\
\text { program }\end{array}$ & $7.93 \pm 1.00$ & 6.54 & $0.00^{* *}$ \\
$\begin{array}{l}\text { After nutrition education } \\
\text { program }\end{array}$ & $8.77 \pm 0.75$ & & \\
$\begin{array}{l}\text { Nutrition awareness } \\
\text { Before nutrition awareness }\end{array}$ & $8.23 \pm 0.90$ & 12.09 & $0.00^{* *}$ \\
After nutrition awareness & $9.10 \pm 0.69$ & & \\
\hline$* *$ Significant at $\mathrm{p}<0.01$. SD: Standard deviation & &
\end{tabular}

considered unhealthy when eaten regularly. Dietary pattern in teen years has been associated with health risks for chronic diseases in adulthood. Inadequate consumption of fruits, vegetables, whole grains with high intake of fat, sodium, and simple carbohydrates results in higher prevalence of overweight among teenage adolescents. A study on the diet quality and nutritional status of rural adolescent girls in North India assessed that subjects followed a two-meal pattern with inadequate consumption of fruits and green leafy vegetables [10].

Inclusion of fruits in the diet is essential as they provide essential nutrients which the body needs also reduces the risk of obesity, stroke, hypertension, and cancer [11]. Consumption of soft drinks which is common among adolescent girls needs to be replaced with other alternative healthy options as soft drinks intake leads to several health issues. One healthy choice would be probiotic drink as it not only promotes the body's natural immunity and maintains the gut microflora [12].

Nutrition education program is a critical component of most major health promotions and diseases prevention programs among adolescents as it is considered to be a cost-effective way to improve health outcomes and foster healthy eating. Such programs bring about significant reduction in BMI, increase fruit and vegetable consumption and also show a positive impact on academic outcomes $[13,14]$. Research shows that 35-50 h per year of focused nutrition education is optimal to provide students with the required motivation and skills they need to make healthy choices [15]

\section{CONCLUSION}

Eating habits learnt during childhood tend to continue into adulthood. From the present study, it is evident that due to social, economic, and cultural influences, adolescent girls had the habit of following unhealthy dietary such as skipping meals, low intake of fruits, and consumption of junk foods that contributes to obesity. Hence, to make them aware about the ill effects of unhealthy diets, planning appropriate nutritional educational strategies is essential. Implementation of such interventional programs for this group of students improves dietary quality, and to avoid unbalanced diets which prevent and delays the onset of chronic illness.

\section{REFERENCES}

1. Geckle J. Use of multimedia or mobile devices by adolescents for health promotion and disease prevention: A literature review. J Pediatr Nurs 2016;42:163-8.

2. McNaughton SA, Ball K, Mishra GD, Crawford DA. Dietary patterns of adolescents and risk of obesity and hypertension. J Nutr 2008; $138: 364-70$

3. Washi SA, Ageib MB. Poor diet quality and food habits are related to impaired nutritional status in 13-to18-year-old adolescents in Jeddah. Nutr Res 2010;30:527-34.

4. Dixon HG, Scully ML, Wakefield MA, White VM, Crawford DA. The effects of television advertisements for junk food versus nutritious food on children's food attitudes and preferences. Soc Sci Med 2007;65:1311-23.

5. Ashakiran, R Deepthi. Fast foods and their impact on health. J Krishna Inst Med Sci Univ 2012;1:7-15.

6. Misra A, Vikram NK, Gupta R, Pandey RM, Wasir JS, Gupta VP. Waist circumference cut off points and action levels for Asian Indians for identification of abdominal obesity. Int J Obes 2006;30:106-111.

7. Chin YS, Nasir MT. Eating behaviours among female adolescents in Kuantan District, Pahang, Malaysia. Pak J Nutr 2009;8:425-32.

8. Noh JW, Kim YE, Oh IH, Kwon YD. Influences of socioeconomic factors on childhood and adolescent overweight by gender in Korea: Cross-sectional analysis of nationally representative sample. BMC Public Health 2014;14:324.

9. Story M, Neumark-Sztainer D, French S. Individual and environmental influences on adolescent eating behaviours. J Am Diet Assoc 2002;102:40-51.

10. Malhotra A, Passi SJ. Diet quality and nutritional status of rural adolescent girl beneficiaries of ICDS in north India. Asia Pac J Clin Nutr 2007;16 Suppl 1:8-16.

11. Shafi S. Some uncommon fruits of the amazing world. Int J Pharm Pharm Sci 2014;6:54-8.

12. Vemuri PK, Velampati RH, Tipparaju S. Probiotics: A novel approach in improving the values of human life. Int J Pharm Pharm Sci 2014;6:41-3.

13. Pucher KK, Boot NM, De Vries NK. School health promotion interventions targeting physical activity and nutrition can improve academic performance in primary-and middle school children. Health Educ 2012;55:372-91

14. Silveira JA, Taddei JA, Guerra PH, Nobre MR. The effect of participation in school-based nutrition education interventions on body mass index: A meta-analysis of randomized controlled community trials. Prev Med 2013;56:237-43.

15. Prelip M, Kinsler J, Thai CL, Erausquin JT, Slusser W. Evaluation of a school-based multicomponent nutrition education program to improve young children's fruit and vegetable consumption. J Nutr Educ Behav 2012;44:310-8.Id qui res aspe parum quodi sum dignateLate ipsam, 